\title{
MECHANISMS OF BETA-LACTAM RESISTANCE IN BRITISH ISOLATES OF PSEUDOMONAS AERUGINOSA
}

\author{
Rosamund J. Williams, D. M. Livermore, M. A. Lindridge, A. A. Said \\ AND J. D. Williams
}

Department of Medical Microbiology, The London Hospital Medical College, Turner Street, London E1 $2 A D$

\begin{abstract}
SUMmARY. The mechanisms of resistance to beta-lactam antibiotics in 191 isolates of Pseudomonas aeruginosa were examined. These represented the most resistant organisms of 1866 isolates collected during a national survey of antibiotic resistance in this species. One hundred and seventy-two isolates were selected because they were resistant to carbenicillin (MIC > $128 \mathrm{mg} / \mathrm{L}$ ) and 19 because the MICs of cefotaxime were greater than the MICs of carbenicillin. Of the carbenicillin-resistant isolates, 35 produced plasmid-mediated beta-lactamases known to be active against carbenicillin and seven produced unusual beta-lactamases; in 131 strains, resistance could not be attributed to beta-lactamase production and was considered to be intrinsic. The unusual antibiogram in which the MIC of cefotaxime was greater than the MIC of carbenicillin was associated with overproduction of the chromosomally-determined Sabath and Abrahams' beta-lactamase. Selection of strains with this last mechanism represents a novel resistance problem and one which may increase with increased use of newer antipseudomonal beta-lactams.
\end{abstract}

\section{INTRODUCTION}

Pseudomonas aeruginosa is typically susceptible to several newer semi-synthetic beta-lactams including carboxy- and ureidopenicillins, cephalosporins, monobactams and thienamycin (Zak, 1980; Sykes et al., 1981; Gillett, 1982). However strains resistant to some or all of these agents have been widely reported. Most of these reports concern a few selected strains and are not necessarily representative of the current resistance situation. We have recently conducted a multicentre survey to determine the prevalence of antibiotic resistance in $P$. aeruginosa. During the period from February to May 1982, consecutive, non-replicate, clinical isolates of $P$. aeruginosa were collected from 24 hospitals in all parts of the UK (Williams et al., in press). A total of 1991 isolates were received, of which 1866 were confirmed as $P$. aeruginosa. The susceptibility of these organisms to the beta-lactams carbenicillin, 
azlocillin, cefotaxime, cefoperazone and ceftazidime and the aminoglycosides gentamicin and amikacin was tested by the agar dilution technique and the results have been reported elsewhere (Williams et al., in press).

The mode MIC values of the beta-lactams for the 1866 P. aeruginosa isolates were: carbenicillin $64 \mathrm{mg} / \mathrm{L}$; azlocillin $8 \mathrm{mg} / \mathrm{L}$; cefotaxime $16 \mathrm{mg} / \mathrm{L}$; cefoperazone $4 \mathrm{mg} / \mathrm{L}$ and ceftazidime $1 \mathrm{mg} / \mathrm{L}$. A small minority of the isolates were more resistant and the aim of the present investigation was to study the mechanisms of resistance of these organisms.

From the original collection of 1866 strains of $P$. aeruginosa, all 172 isolates with a carbenicillin MIC $>128 \mathrm{mg} / \mathrm{L}$ were examined. During the course of the survey, a few strains with an unusual susceptibility pattern were observed; they were more resistant to cefotaxime than to carbenicillin. A report on five of these strains has already been published (Livermore et al., 1982). The only beta-lactamase detected in them was chromosomal Sabath and Abrahams' (SA) enzyme produced by all wild type $P$. aeruginosa. However the production of SA enzyme in these five strains was greatly in excess of normal. Therefore, in addition to studying isolates that were resistant to carbenicillin, we also examined isolates from the survey which showed this unusual antibiogram.

\section{MATERIALS AND METHODS}

Bacterial strains. From the total survey collection of 1866 strains of $P$. aeruginosa, 191 resistant isolates were examined. One hundred and seventy two of these isolates were selected because they were resistant to carbenicillin (MIC $>128 \mathrm{mg} / \mathrm{L}$ ). The remaining 19 isolates were selected as possible overproducers of SA enzyme. Reference $P$. aeruginosa strains used for comparative studies were the fully susceptible strain R20 (Livermore, Williams and Williams, 1981), the Sabath and Abrahams' (SA) beta-lactamase derepressed mutants (Ps.50 SAI ${ }^{\text {on } 1 \text { and } 2 \text { ) }}$ (Livermore, 1983a) and several strains that produced various plasmid-determined carbenicillinhydrolysing beta-lactamases (Livermore et al., 1981; Livermore and Williams, 1982).

Antibiotics. The following antibiotic powders were kindly provided by the manufacturers: azlocillin (Bayer UK Ltd); carbenicillin (Beecham); cefoperazone (Pfizer Inc.); cefotaxime (Roussel); ceftazidime (Glaxo) and cloxacillin (Beecham). They were stored at $4^{\circ} \mathrm{C}$ and solutions were prepared on the day of use according to the manufacturers' instructions.

Determination of minimum inhibitory concentrations. MICs were determined by the agar dilution technique with Isosensitest agar (Oxoid, CM 471) and inocula of $c .10^{4} \mathrm{cfu}$, as described by Williams et al. (in press).

Beta-lactamase detection. All the isolates were tested for beta-lactamase production with nitrocefin (O'Callaghan et al., 1972). Isolates were grown overnight on nutrient agar and one loopful of culture was emulsified in $25 \mu \mathrm{l}$ of $0.1 \mathrm{M}$ ethylene diaminotetra-acetic acid (EDTA) in $0 \cdot 1 \mathrm{M}$ phosphate buffer $p \mathrm{H} \mathrm{7.0} \mathrm{containing} \mathrm{lysozyme} \mathrm{(Sigma} \mathrm{Chemical} \mathrm{Co.,} \mathrm{St} \mathrm{Louis,} \mathrm{MO.,} \mathrm{USA)}$ $250 \mathrm{mg} / \mathrm{L}$. After $5 \mathrm{~min}, 25 \mu \mathrm{l}$ of $1.0 \mathrm{~mm}$ nitrocefin (Glaxo Group Research) were added and a colour change to deep red within $15 \mathrm{~min}$ was considered to be a positive reaction. When a positive reaction was obtained, the tests were repeated with $0.1 \mathrm{~mm}$ cloxacillin included in the nitrocefin solution; this tested for inhibition of the beta-lactamase activity by cloxacillin. Previous experiments performed in our laboratory indicated that the EDTA nitrocefin test gave a very weak positive reaction with typical, beta-lactam susceptible $P$. aeruginosa such as the control strain R20 and this reaction was completely inhibited by cloxacillin. Control strains that produced various plasmid-mediated beta-lactamases gave moderately to strongly positive reactions that were, at most, only weakly inhibited by cloxacillin. Isolates that produced PSE-3 beta-lactamase were exceptional; they gave only a weakly positive result. The Ps.50 SAI ${ }^{\mathrm{con} 1}$ and con 2 mutants with constitutive expression of chromosomal SA beta-lactamase gave strongly positive reactions, substantially inhibited by cloxacillin.

Beta-lactamase identification. Strains shown to be beta-lactamase producers by the above 
method were grown overnight on nutrient agar slopes and the growth was washed off into 0.75

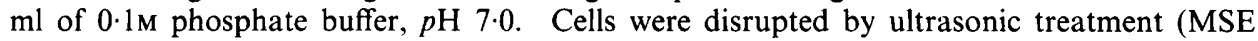
Ultrasonic Disintegrator, MSE Instruments, Crawley, Sussex) and cellular debris deposited by centrifugation at $12000 \mathrm{~g}$. Portions from the supernatant fractions were subjected to isoelectric focusing in $7 \%$ polyacrylamide gels containing $2 \%$ Pharmalyte (Pharmacia Fine Chemicals, Uppsala, Sweden) (Matthew et al., 1975). After focusing, beta-lactamases were detected by flooding the gel with $1.0 \mathrm{~mm}$ nitrocefin and were identified by isoelectric point $(\mathrm{pI})$ and by alignment with known standard enzymes. Various $p \mathrm{H}$ range Pharmalytes were used. Extracts were initially focused on broad $p \mathrm{H}$ range gels $(p \mathrm{H} \mathrm{3-10)}$ to give an approximate $\mathrm{pI}$. Focusing was then repeated on an appropriate narrow range gel $(p \mathrm{H} 4-6 \cdot 5 ; 5-8 ; 6 \cdot 5-9)$ to confirm enzyme identity.

Beta-lactamase production in SA enzyme depressed strains. Early in the survey five isolates of $P$. aeruginosa with an unusual antibiogram were collected. The only detectable beta-lactamases produced by them had pIs in the range 7.4-8.8 (Livermore et al., 1982). When the survey was completed, another 14 isolates were found to resemble the original five. These 19 isolates were tested for inducibility of SA enzyme production by cefoxitin. Organisms were grown overnight in $10 \mathrm{ml}$ of nutrient broth at $37^{\circ} \mathrm{C}$ with orbital shaking at $150 \mathrm{rpm}$ and $1-\mathrm{ml}$ volumes of these cultures were used to inoculate duplicate $9-\mathrm{ml}$ volumes of fresh broth warmed to $37^{\circ} \mathrm{C}$. After incubation for $90 \mathrm{~min}$, cefoxitin was added to one broth (induced culture) to a final concentration of $500 \mathrm{mg} / \mathrm{L}$. No additions were made to the second broth (uninduced culture). Incubation was continued for $4 \mathrm{~h}$ at $37^{\circ} \mathrm{C}$. Induction was then terminated by additing $1 \mathrm{~mm}$ 8-hydroxyquinoline (Sigma) (Sabath, Jago and Abraham, 1965). Cells were harvested by centrifugation at $6000 \mathrm{~g}$, washed once in $0.1 \mathrm{M}$ phosphate buffer, $\mathrm{pH} 7.0$ and ultrasonically disrupted. The beta-lactamase content of the sonicates was determined by spectrophotometric assay with $0.1 \mathrm{~mm}$ nitrocefin as substrate (O'Callaghan et al., 1972). A Pye Unicam SP8-100 UV recording spectrophotometer was used. Beta-lactamase yields were standardised against protein concentrations determined by the method of Lowry et al. (1951) with bovine serum albumin (Sigma) standards.

\section{RESULTS}

The survey of antibiotic resistance in $P$. aeruginosa in the UK revealed 172 isolates $(9 \cdot 2 \%$ of the total collection) with carbenicillin MICs $>128 \mathrm{mg} / \mathrm{L}$ and 19 isolates for which the MIC of cefotaxime was greater than that of carbenicillin. The 191 isolates were divided into three groups on the basis of beta-lactamase production characteristics and antibiogram. Group 1 comprised 41 isolates that gave a strong EDTA nitrocefin reaction which was not inhibited by cloxacillin. Beta-lactamases produced by these isolates are listed in table I. Thirty-five organisms produced beta-lactamases recognised by Matthew (1979) as plasmid-mediated carbenicillinases. PSE-4 (Dalgleish enzyme; Newsom, Sykes and Richmond, 1970) was the most frequently encountered of these enzymes; it was produced by 18 isolates from eight hospitals. Isolates with TEM-1, OXA-1, PSE-1, PSE-2 and PSE-3 enzymes were also encountered. Organisms that produced these enzymes had a very characteristic antibiogram; all were resistant to carbenicillin and azlocillin ( $\mathrm{MIC}>32 \mathrm{mg} / \mathrm{L}$ ), many were resistant to cefoperazone (MIC $>16 \mathrm{mg} / \mathrm{L}$ ), but all were fully susceptible to cefotaxime and ceftazidime (fig. 1). The other six Group-1 isolates synthesised enzymes that did not co-focus with recognised plasmid-mediated beta-lactamases. Two of these organisms, which were from the same hospital and of the same serotype, produced an enzyme with a pI of 6.5. This enzyme hydrolysed carbenicillin and was encoded by a transferable element (Livermore, unpublished finding). Although the pI was the same as that reported for the LCR-1 beta-lactamase by Simpson et al. (1983), the present enzyme focused between PSE- 2 and PSE- 3 whereas LCR-1 focuses between PSE-1 and PSE-2. 
TABLE I

Beta-lactamases produced by Group I isolates of P. aeruginosa

\begin{tabular}{lcc}
\hline \multicolumn{1}{c}{ Enzyme } & $\begin{array}{c}\text { Number of } \\
\text { isolates that } \\
\text { produced the enzyme }\end{array}$ & $\begin{array}{c}\text { Number of hospitals that } \\
\text { returned these isolates }\end{array}$ \\
\hline Plasmid-mediated* & & \\
PSE-4 & 18 & 8 \\
OXA-1 & $10 \dagger$ & 4 \\
TEM-1 & $4 \dagger$ & 1 \\
PSE-2 & 2 & 1 \\
PSE-1 & 1 & 1 \\
PSE-3 & 1 & 1 \\
Novel enzymes & 2 & 1 \\
pI 6.5 & 3 & 1 \\
pI 7.8 & 1 & \\
pI 8 & & \\
\hline
\end{tabular}

*According to Matthew (1979); $\uparrow$ one isolate produced both TEM-1 and OXA-1.

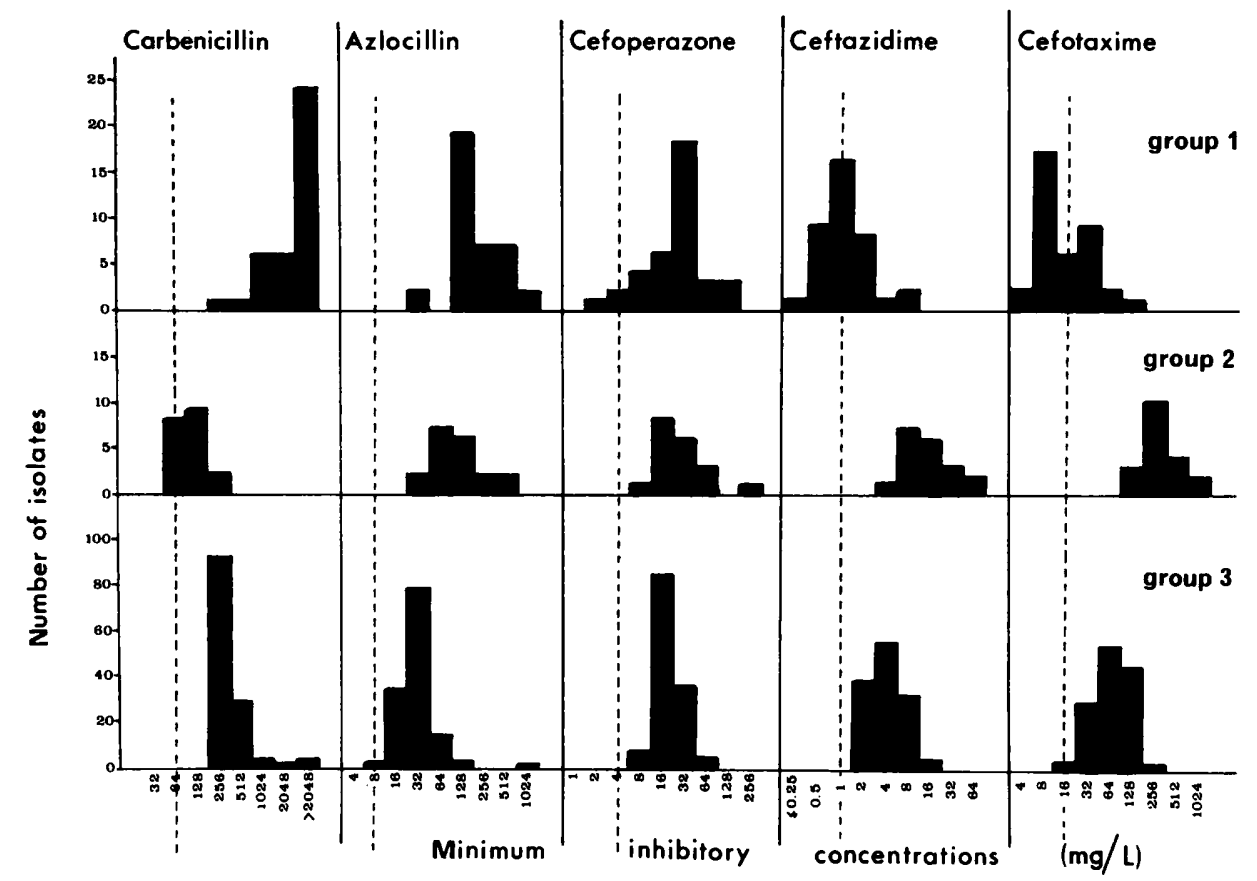

FIG. 1.-Distribution of minimum inhibitory concentrations of five beta-lactams for isolates of $P$. aeruginosa in resistance groups 1,2 and 3. Mode MIC values for collection of 1866 isolates. Resistance in Group I (41 isolates) is thought to be due to production of plasmid-mediated beta-lactamases. Resistance in Group 2 (19 isolates) is due to overproduction of SA beta-lactamase. Resistance in Group 3 (131 isolates) is not associated with beta-lactamase production but is thought to be intrinsic. 
The two enzymes also differed in substrate specificity. The isolates with this $\mathrm{pI} 6.5$ enzyme had an antibiogram analogous to that of organisms that produced plasmidmediated beta-lactamases listed by Matthew (1979).

The remaining four isolates belonged to Group 1 by virtue of their beta-lactamase production and did not exhibit the antibiogram described above. MICs of carbenicillin for these organisms never exceeded $256 \mathrm{mg} / \mathrm{L}$ although MICs of azlocillin and cefoperazone were between two and three doubling dilutions higher than the mode values for these agents. Three of these isolates came from the same hospital burns unit and were of the same serotype $(\mathrm{O}: 6)$. Isoelectric focusing demonstrated a beta-lactamase with a pI of $7 \cdot 8$ which focused between SHV-1 (pI 7.6) and OXA-2 (pI 8.2) beta-lactamases and was also distinct from SA enzyme. Although we have not yet demonstrated that it is plasmid-mediated, the $\mathrm{pI} 7.8$ enzyme shows a strong resemblance to the OXA class of plasmid-mediated beta-lactamases; it is fourfold more active against $500 \mu \mathrm{M}$ oxacillin than $500 \mu \mathrm{m}$ benzyl penicillin. It has a mol. wt of 40,000 ( \pm 2000 ) estimated by column chromatography and may be identical with the OXA- 6 enzyme described by Medeiros and Jacoby (1982). Production of the pI $7 \cdot 8$ enzyme was detected in a further six carbenicillin-susceptible serotype 0:6 isolates from the same hospital unit. The fourth isolate was from another hospital and produced a beta-lactamase with an isoelectric point $>8$; this may be an unusual form of SA enzyme and is being investigated.

TABLE II

Production of $S A$ beta-lactamase by Group-2 isolates

\begin{tabular}{|c|c|c|c|}
\hline \multirow[b]{2}{*}{ Isolate } & \multirow[b]{2}{*}{ Source } & \multicolumn{2}{|c|}{$\begin{array}{l}\text { Enzyme production } \\
\left(\mathbf{U}^{*} / \mathrm{mg} \text { protein }\right)\end{array}$} \\
\hline & & Uninduced & $\begin{array}{l}\text { Induced with } \\
\text { cefoxitin } 500 \mathrm{mg} / \mathrm{L}\end{array}$ \\
\hline M1505 & Plymouth & 63 & 9740 \\
\hline M2612 & Nottingham & 71 & 5100 \\
\hline M78 & Aberdeen & 203 & 5290 \\
\hline M1472 & Nottingham & 218 & 6570 \\
\hline M126 & Irvine & 396 & 3660 \\
\hline M2660 & Nottingham & 413 & 7950 \\
\hline M1496 & Nottingham & 492 & 2500 \\
\hline M2318 & LHMC, London & 510 & 4380 \\
\hline M2598 & Nottingham & 617 & 12480 \\
\hline M84 & Aberdeen & 840 & 13200 \\
\hline M517 & Bristol & 860 & 6290 \\
\hline M2320 & LHMC, London & 916 & 3810 \\
\hline M1511 & $\begin{array}{l}\text { Plymouth } \\
\text { Plo }\end{array}$ & 1082 & 36500 \\
\hline M1297 & Liverpool & 1125 & 10700 \\
\hline M848 & Guy's London & 1197 & 8700 \\
\hline M1298 & Liverpool & 1361 & 10700 \\
\hline M2002 & UCH, London & 1490 & 13300 \\
\hline M2297 & Newcastle & 10200 & 13300 \\
\hline M1405 & Nottingham & 42100 & 68000 \\
\hline \multirow{3}{*}{\multicolumn{2}{|c|}{$\begin{array}{l}\text { Controls } \\
\text { R20 LHMC, London } \\
14 \text { isolates selected at ran- } \\
\text { dom }\end{array}$}} & & \\
\hline & & 18 & 650 \\
\hline & & $16 \cdot 5$ & $\ldots$ \\
\hline
\end{tabular}

* One unit $(\mathrm{U})$ of enzyme activity hydrolysed $1 \mathrm{nmol}$ of nitrocefin $/$ min at a nitrocefin concentration of $100 \mu \mathrm{M}$ at $37^{\circ} \mathrm{C}$. 
Group 2 consisted of the 19 isolates that were unusually resistant to cefotaxime, for which the MIC was greater than the MIC of carbenicillin, and included the five known overproducers of SA enzyme. These organisms were also moderately resistant to azlocillin, cefoperazone and ceftazidime, when the MICs were compared with mode values for these antibiotics, but were usually susceptible to carbenicillin (fig. 1). All these isolates gave moderate to strong reactions with EDTA nitrocefin which were substantially inhibited by cloxacillin. Beta-lactamases extracted from the Group 2 isolates did not align with known plasmid-mediated enzymes but focused at various isoelectric points within the $p \mathrm{H}$ range 7.4-8.8. Previous studies have described SA beta-lactamase as focusing within this range (Matthew and Harris, 1976; Furth, 1979). The results obtained with the Group- 2 isolates resembled those obtained previously with SA beta-lactamase derepressed control strains, and it was concluded that resistance in this group involved derepression of SA enzyme biosynthesis resulting in overproduction of this enzyme.

Tests for induction of SA enzyme by cefoxitin showed that 17 of the 19 Group-2 isolates had retained inducibility but synthesised unusually high basal levels of this enzyme (table II). Two isolates were totally derepressed; they synthesised almost equally large amounts of enzyme in the presence and absence of cefoxitin. The

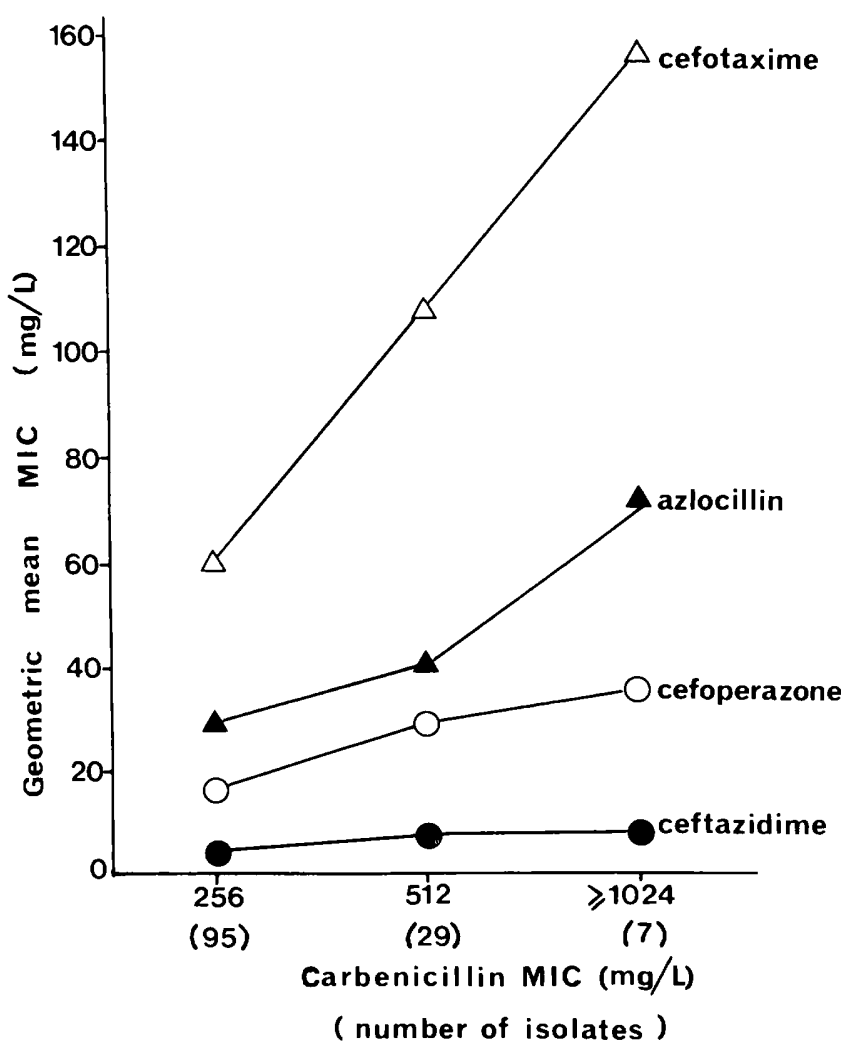

FIG. 2.-Relationship of carbenicillin MIC to mean MICs of other beta-lactams for Group-3 isolates. 
uninduced beta-lactamase expression by these constitutive organisms was $>1000$-fold greater than the basal enzyme expression in typical $P$. aeruginosa.

Group 3 comprised 131 isolates resistant to carbenicillin and relatively insusceptible, compared with mode MIC values, to the other four beta-lactams tested (fig. 1). Isolates in this group with MICs of carbenicillin $>1024 \mathrm{mg} / \mathrm{L}$ were more resistant to the other beta-lactams than those isolates with carbenicillin MICs of $256-512 \mathrm{mg} / \mathrm{L}$. This was most marked for cefotaxime and least for ceftazidime (fig. 2). Isolates in Group 3 gave only a very weak reaction with EDTA nitrocefin which was inhibited by cloxacillin and, therefore, characteristic of normal basal levels of SA enzyme.

\section{Discussion}

The beta-lactam resistance of $P$. aeruginosa seems to pose two separate problems. First, typical $P$. aeruginosa strains are relatively insusceptible to many beta-lactams in comparison with other gram-negative rods. This intrinsic resistance depends upon a combination of cell impermeability and production of the chromosomally-determined SA beta-lactamase (Ohmori et al., 1977; Zimmermann, 1980; Curtis et al., 1981). Second, strains may exhibit increased resistance, rendering them insusceptible to clinically achievable concentrations of some or all of the antipseudomonal beta-lactams. The present study investigated the mechanisms underlying the latter phenomenon.

The survey of antibiotic resistance in P. aeruginosa in 1982 (Williams et al., in press) and another recent multi-centre study (King et al., 1980) demonstrated that increased resistance was infrequent in clinical practice in the UK. Only c. $10 \%$ of the isolates collected from 24 hospitals in the 1982 survey (Williams et al., in press) were considered to be resistant to carbenicillin. However, resistance rates varied markedly between hospitals.

The resistance to carbenicillin, azlocillin and cefoperazone of the 35 out of 41 Group- 1 isolates that produced recognised plasmid-mediated beta-lactamases was in close accord with the reported hydrolytic activity of these enzymes. Phillips et al. (1981), Li and Williams (1982) and Livermore and Williams (1982) all found that cefoperazone, azlocillin and carbenicillin were substrates for these enzymes, whereas cefotaxime and ceftazidime were relatively stable. These correlations also applied to the two isolates with the novel pI 6.5 enzyme and, therefore, there seem to be good reasons for classifying this enzyme with those listed by Matthew (1979). The most noteworthy feature of these Group-1 $P$. aeruginosa strains with plasmid-mediated beta-lactamases is the infrequency of their isolation. $P$. aeruginosa isolates with enzymes of this type were first described by Lowbury et al. (1969) and it was feared that increasing use of carbenicillin might select for enzyme-producing isolates. Evidently these fears were misplaced; only $2 \%$ of 1866 isolates collected in this survey possessed such enzymes. These results contrast with the high frequency of such enzymes in enterobacteria (Stobberingh, Houben and van Boven, 1982; Whitaker, Hajipieris and Williams, in press). It may be that the limited transmissibility of many plasmids into and within $P$. aeruginosa (Jacoby, 1978; Furth, 1979) has acted to restrict the enzyme dissemination in this species.

The high frequency of PSE-4 enzyme production amongst the strains was surprising. TEM-1 is the most common plasmid-mediated beta-lactamase produced 
by gram-negative bacteria in general (Stobberingh et al., 1982; Whitaker et al., 1983). PSE-4 is confined to $P$. aeruginosa (Jacoby and Matthew, 1979) and its production has recently been shown to be encoded by the non-conjugative chromosomally-integrating transposon Tn2521 (Sinclair and Holloway, 1982). Perhaps this element has been widely disseminated in $P$. aeruginosa; we are currently examining our strains for transposability of their PSE-4 character.

The four isolates within Group 1 that did not produce plasmid-mediated enzymes listed by Matthew (1979) nor the pI 6.5 beta-lactamase were unusual, and the role in resistance played by their beta-lactamases is unclear. The detection of the pI $7 \cdot 8$ enzyme in carbenicillin-susceptible isolates from the same source as the resistant organisms that produced this enzyme suggested that it was not a useful defence against carbenicillin. However, it may be more important against cefoperazone which appears to be a better substrate in vitro.

The Group-2 isolates (carbenicillin-susceptible cefotaxime- and azlocillin-resistant) represent a new and disturbing development. This mechanism of resistance appears to involve partial or total derepression of the synthesis of the chromosomallyspecified SA beta-lactamase. Whereas typical $P$. aeruginosa strains synthesise only basal levels of enzyme in the absence of inducers (Nordström and Sykes, 1974), the resistant isolates synthesise substantially larger amounts. It has been demonstrated that cefotaxime, cefoperazone and azlocillin are hydrolysed significantly by SA enzyme and ceftazidime is slightly labile (Livermore, 1983 $a$ and $b$; Jacobs, Livermore and Davy, in press). The activity of these agents as measured in agar MIC tests with fully inducible $P$. aeruginosa depends upon failure to induce enzyme biosynthesis. When SA beta-lactamase expression becomes partially or wholly independent of induction as in the Group-2 isolates and in laboratory mutants, its activity is reflected in the MIC values obtained. In contrast, carbenicillin is stable to and a potent inactivator of SA enzyme (Furth, 1979). Thus, the antibiograms of Group-2 isolates reflect the hydrolytic activity of SA enzyme when produced in excess. Two Group-2 isolates were fully constitutive in their production of SA enzyme. Investigation of the clinical histories of these isolates reveals that they had been obtained from two patients who had been treated for 14 days with cefotaxime and ceftazidime respectively. In one patient there was good evidence for the evolution of the $P$. aeruginosa isolate from SA-inducible to SA-constitutive during the course of therapy. Similar in-vivo selection of SA-derepressed $P$. aeruginosa during azlocillin therapy has been reported (Shannon, King and Phillips, 1982) and it is feared that increasing use of the newer anti-pseudomonal beta-lactams may be accompanied by an increase in the incidence of this type of resistance.

The most common type of resistance, which was found in 131 out of $191(69 \%)$ of resistant strains, involved a decrease in susceptibility to all five beta-lactams tested. Beta-lactamases did not appear to be responsible and would seem an unlikely mechanism for such broad spectrum resistance. Intrinsic mechanisms such as decreased outer membrane permeability or reduced target penicillin binding protein (PBP) susceptibility have been proposed to explain this resistance. The former seems the more likely because we have been unable to detect PBP resistance in a number of isolates tested in our laboratory. However other mechanisms such as more rapid breakdown in beta-lactam-PBP complexes, more rapid synthesis of new PBP enzymes, or increased non-specific beta-lactam binding, have not been excluded. 
We are very grateful to all the members of the study group who participated in the survey: Dr C.A.Bartzokas, University of Liverpool, Liverpool; Dr T.D.Brogan, Stepping Hill Hospital, Stockport; Dr G.M.Churcher, Plymouth General Hospital, Plymouth; Dr Y.Drabu, University College Hospital, London; Dr F.X.S.Emmanuel, Western General Hospital, Edinburgh; Dr R.J.Fallon, Ruchill Hospital, Glasgow; Dr L.A.Ganguli, Hope Hospital, Salford; Dr A.J.Howard, Caernarfon and Anglesey Hospital, Bangor; Dr D.A.Leigh, Wycombe General Hospital, High Wycombe; Dr M.J.Lewis, University Hospital, Nottingham; Dr R.McGill, Ayrshire General Hospital, Irvine; Dr O.A.Okubadejo, St.Mary's General Hospital, Portsmouth; Dr R.N.Peel, York District Hospital, York; Professor I.Phillips, St. Thomas' Hospital, London; Dr I.A.Porter, City Hospital, Aberdeen; Dr D.S.Reeves, Southmead General Hospital, Bristol; Dr M.H.Robertson, Princess Alexandra Hospital, Harlow; Dr J.Selkon, General Hospital, Newcastle upon Tyne; Dr N.A.Simmons, Guy's Hospital, London; Dr R.M.Stirland, Manchester Royal Infirmary, Manchester; Dr A.B.White, Raigmore Hospital, Inverness; Dr W.D.White, Barking Hospital, Barking; and Dr R.Wise, Dudley Road Hospital, Birmingham.

We thank Dr T. Pitt and his colleagues at the Central Public Health Laboratory, Colindale for serotyping some of the isolates and we are grateful to Pfizer Inc. for a generous grant to The London Hospital Medical College which, to a large extent, defrayed the cost of the survey.

\section{REFERENCES}

Curtis N A C, Orr D, Boulton M G, Ross G W 1981 Penicillin binding proteins of Pseudomonas aeruginosa: comparison of two strains differing in their resistance to beta-lactam antibiotics. Journal of Antimicrobial Chemotherapy 7:127-136.

Furth A 1979 The beta-lactamases of Pseudomonas aeruginosa. In Hamilton-Miller JMT, Smith JT (eds) Beta-lactamases. Academic Press, London, pp 403-428.

Gillet A P 1982 Antibiotics against Pseudomonas aeruginosa. Journal of Antimicrobial Chemotherapy 8:Suppl B, 41-48.

Jacobs J Y, Livermore D M, Davy K W M Studies on the role of Pseudomonas aeruginosa beta-lactamase as a defence against azlocillin, mezlocillin and piperacillin. Journal of Antimicrobial Chemotherapy, in press.

Jacoby G A 1978 Classification of plasmids in Pseudomonas aeruginosa. In: Schlessinger D (ed) Microbiology 1977. American Society for Microbiology, Washington D.C. pp 119-126.

Jacoby G A, Matthew M 1979 The distribution of beta-lactamase genes on plasmids found in Pseudomonas. Plasmid 2:41-47.

King J D, Farmer T, Reading C, Sutherland R 1980 . Sensitivity to carbenicillin and ticarcillin and the beta-lactamases of Pseudomonas aeruginosa in the UK in 1978-1979. Journal of Clinical Pathology 33:297-301.

Li J T, Williams J D 1982 Comparative activity of furbenicillin and carbenicillin-like compounds. Journal of Antimicrobial Chemotherapy 9:171-181.

Livermore D M 1983a Kinetics and significance of the activity of Sabath and Abrahams' beta-lactamase of Pseudomonas aeruginosa against cefotaxime and cefsulodin. Journal of Antimicrobial Chemotherapy 11:169-179.

Livermore D M 1983b Resistance mechanisms of Pseudomonas aeruginosa to beta-lactam antibiotics. PhD Thesis, University of London.

Livermore D M, Williams R J 1982 Role of plasmid-mediated beta-lactamases in the resistance of Pseudomonas aeruginosa to new beta-lactams. In: Periti P, Grassi G G (eds) Current chemotherapy and immunotherapy. American Society for Microbiology, Washington DC, pp 754-756.

Livermore D M, Williams R J, Lindridge M A, Slack R C B, Williams J D 1982 Pseudomonas aeruginosa isolates with modified beta-lactamase inducibility: effects on beta-lactam sensitivity. Lancet 1:1466-1467.

Livermore D M, Williams R J, Williams J D 1981 Comparison of the beta-lactamase stability and the in vitro activity of cefoperazone, cefotaxime, cefsulodin, ceftazidime, moxalactam and ceftriaxone against Pseudomonas aeruginosa. Journal of Antimicrobial Chemotherapy 8:323-331. 
Lowbury E J L, Kidson A, Lilly H A, Ayliffe G A J, Jones R J 1969 Sensitivity of Pseudomonas aeruginosa to antibiotics: emergence of strains highly resistant to carbenicillin. Lancet 2:448-452.

Lowry O H, Rosebrough N J, Farr A L, Randall R J 1951 Protein measurement with the folin phenol reagent. Journal of Biological Chemistry 193:265-275.

Matthew M 1979 The plasmid-mediated beta-lactamases of gram-negative bacteria: properties and distribution. Journal of Antimicrobial Chemotherapy 5:349-358.

Matthew M, Harris A M 1976 The identification of beta-lactamases by analytical isoelectric focusing: correlation with bacterial taxonomy. Journal of General Microbiology 94:55-67.

Matthew M, Harris A M, Marshall M J, Ross G W 1975 The use of analytical isoelectric focusing for detection and identification of beta-lactamases. Journal of General Microbiology 88:169-178.

Medieros A A, Jacoby G A 1982 Abstract 716. 22nd Interscience Conference of Antimicrobial Agents and Chemotherapy, American Society for Microbiology, Washington, DC.

Newsom S W B, Sykes R B, Richmond M H 1970 Detection of a beta-lactamase markedly active against carbenicillin in a strain of Pseudomonas aeruginosa. Journal of Bacteriology 101:1079-1080.

Nordström K, Sykes R B 1974 Induction kinetics of beta-lactamase biosynthesis in Pseudomonas aeruginosa. Antimicrobial Agents and Chemotherapy 6:734-740.

O'Callaghan C H, Morris A, Kirby S M, Shingler A H 1972 Novel method for detection of beta-lactamases using a chromogenic cephalosporin substrate. Antimicrobial Agents and Chemotherapy 1:283-288.

Ohmori H, Azuma A, Suzuki Y, Hashimoto Y 1977 Factors involved in beta-lactam antibiotic resistance in Pseudomonas aeruginosa. Antimicrobial Agents and Chemotherapy 12:537-539.

Phillips I, Warren C, Shannon K, King A, Hanslo D 1981 Ceftazidime: in vitro antibacterial activity and susceptibility to beta-lactamases compared with that of cefotaxime, moxalactam and other beta-lactam antibiotics. Journal of Antimicrobial Chemotherapy 8: Suppl B, 23-31.

Richmond M H, Sykes R B 1973 The beta-lactamases of gram-negative bacteria and their possible physiological role. Advances in Microbial Physiology 9:31-88.

Sabath L D, Jago M, Abraham E P 1965 Cephalosporinase and penicillinase activities of a beta-lactamase from Pseudomonas pyocyanea. Biochemical Journal 96:739-752.

Shannon K, King A, Phillips I 1982 Development of resistance to beta-lactam antibiotics during therapy of Pseudomonas aeruginosa infections. Lancet 1:1466.

Simpson I N, Plested S J, Budin-Jones M J, Lees J, Hedges R W, Jacoby G A 1983 Characterisation of a novel plasmid-mediated beta-lactamase and its contribution to beta-lactam resistance in Pseudomonas aeruginosa. FEMS Microbiology Letters 19:23-27.

Sinclair M I, Holloway B W 1982 A chromosomally located transposon in Pseudomonas aeruginosa. Journal of Bacteriology 151:569-579.

Stobberingh E E, Houben A W, van Boven P A 1982 Distribution and characterisation of beta-lactamase-producing strains isolated in the southern part of The Netherlands. In: Periti P, Grassi G G (eds) Current chemotherapy and immunotherapy, American Society for Microbiology, Washington DC, pp 747-748.

Sykes R B, Bonner D P, Bush K, Georgopapadakou N H, Wells J S 1981 Monobactamsmonocyclic beta-lactam antibiotics produced by bacteria. Journal of Antimicrobial Chemotherapy 8: Suppl E, 1-16.

Sykes R B, Matthew M 1976 The beta-lactamases of gram-negative bacteria and their role in resistance to beta-lactam antibiotics. Journal of Antimicrobial Chemotherapy 2:115-157.

Whitaker S, Hajipieris P, Williams J D Distribution and type of beta-lactamase against 1,000 gram-negative bacteria. Proceedings of the 13th International Congress of Chemotherapy (in press).

Williams R J, Lindridge M A, Said A, Livermore D M, Williams J D National survey of antibiotic resistance in Pseudomonas aeruginosa. Journal of Antimicrobial Chemotherapy, in press. 
Zak O 1980 Antibiotics and Pseudomonas aeruginosa. In Sabath L D, (ed) Pseudomonas aeruginosa, the organism, the diseases it causes and their treatment. Hans Huber, Berne, pp 133-159.

Zimmermann W 1980 Penetration of beta-lactam antibiotics into their target enzymes in Pseudomonas aeruginosa: comparison of a highly sensitive mutant with its parent strain. Antimicrobial Agents and Chemotherapy 18:94-100. 